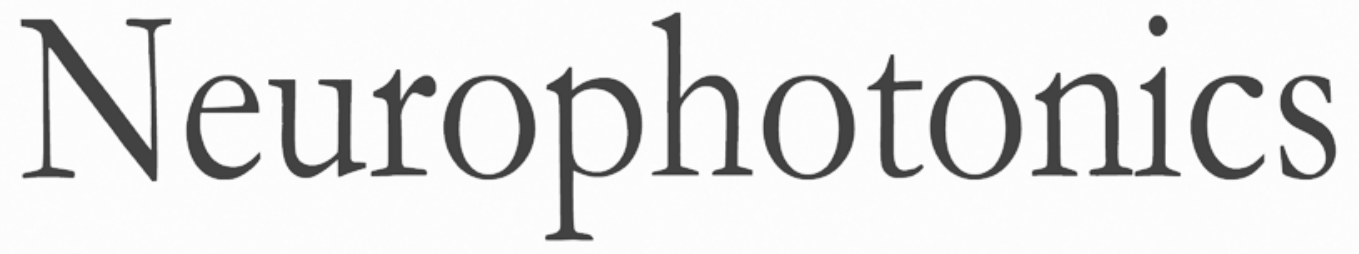

\title{
In vivo validation of cerebral near- infrared spectroscopy: a review
}

\author{
Amalie la Cour \\ Gorm Greisen \\ Simon Hyttel-Sorensen
}




\title{
In vivo validation of cerebral near-infrared spectroscopy: a review
}

\author{
Amalie la Cour, ${ }^{a, \star}$ Gorm Greisen, ${ }^{b}$ and Simon Hyttel-Sorensen ${ }^{b}$ \\ ${ }^{a}$ Hospital South West Jutland, Department of Children, Esbjerg, Denmark \\ ${ }^{b}$ National University Hospital, Department of Neonatology, Rigshospitalet, Copenhagen, Denmark
}

\begin{abstract}
We summarize the available in vivo validation of cerebral near-infrared spectroscopy (NIRS) oximetry to inform future in vivo validation strategies. In particular, to establish a way forward in the assessment of NIRS instrumentation for future randomized trials, a systematic literature search is performed. The records are screened and abstracts are assessed to select studies fulfilling our inclusion criteria. Twenty-two pediatric and 28 adult studies are analyzed after exclusion of three articles in each group. All studies compare regional cerebral tissue oxygenation measured by cerebral NIRS to invasive measurement of central or jugular venous oxygen saturation. In studies without Bland-Altman plots, we extracted data from scatter plots enabling estimation of mean difference (MD), standard deviation (SD), and limits of agreement (LOA). To assess the agreement between $\mathrm{rStO}_{2}$ (regional cerebral tissue oxygenation) estimated by NIRS and by blood samples, weighted averages of the MDs and SDs from each study are calculated. We found a fair agreement between the overall mean of cerebral tissue oxygenation and the mean of a reference value measured by co-oximetry whatever NIRS instrument or site of blood sampling used. Cerebral oxygenation overestimates the reference at low values, some instruments apparently more than others. Thus, a high degree of scatter and a lack of a good reference method complicate in vivo validation of NIRS. It is difficult to draw any firm conclusions despite the large number of studies, and the result of this review leaves us questioning if more of such validation studies of cerebral NIRS oximetry are really needed. Furthermore, the combination of lack of validation and poor repeatability is an important issue when designing a randomized clinical trial of implementing cerebral NIRS oximetry into clinical care. ( 2018 Society of Photo-Optical Instrumentation Engineers (SPIE) [DOI: 10.1117/1.NPh.5.4.040901]
\end{abstract}

Keywords: near infrared spectroscopy; cerebral oximetry; validation.

Paper 18033VRR received Jul. 6, 2018; accepted for publication Oct. 29, 2018; published online Nov. 27, 2018.

\section{Introduction}

Cerebral near-infrared spectroscopy (NIRS) oximetry is increasingly used in clinical care during anesthesia, critical, and neonatal care. Measuring the oxygenation of the brain tissue has an intuitive appeal. Clear evidence for clinical benefits of cerebral NIRS oximetry is, however, still lacking. There are only a few randomized clinical trials (RCT) in the adult population ${ }^{1,2}$ and a single neonatal study on preterm infants, ${ }^{3}$ and none of the studies have sufficient statistical power to detect realistic clinical benefits.

The lack of reliable validated reference values is one of the barriers before implementation of cerebral NIRS oximetry into clinical care is possible. It is a complex task to implement a monitoring system that is known to have nontrivial differences between the different commercially available devices. That may be one reason for the scarcity of trials. Another reason may be that the cerebral tissue oxygenation $\left(\mathrm{rStO}_{2}\right)$ may be simple to understand-it is a value between $0 \%$ and $100 \%$ that represents the hemoglobin oxygen saturation in tissue, but what influences the tissue oxygenation in the brain is less obvious. At any given time, it is a result of a range of different physiological factors, such as cerebral blood flow (CBF), arterial blood oxygen content, ${ }^{4}$ and hence it has been difficult to create reliable criteria for interventions that are suitable for testing in randomized trials.

*Address all correspondence to: Amalie la Cour, E-mail: amalie_lacour@ hotmail.com

\subsection{Near-Infrared Spectroscopy Validation}

The regional tissue oxygenation, $\mathrm{rStO}_{2}$, constitutes in theory a weighted average of arterial, capillary, and venous blood saturation. $\mathrm{rStO}_{2}$ is determined by the arterial oxygen saturation $\left(\mathrm{SaO}_{2}\right)$, the volumes of the arterial $V_{a}$ and venous $V_{v}$ blood, the $\mathrm{CBF}$, the cerebral metabolic rate $\left(\mathrm{CMRO}_{2}\right)$, and the oxygen capacity of the blood defined by the hemoglobin concentration (HB), and the oxygen-binding capacity of $\mathrm{HB}(k)(1.306 \mathrm{~mL}$ of oxygen/g of $\mathrm{HB}):^{5}$

$\mathrm{rStO}_{2}=\mathrm{SaO}_{2}-\frac{V_{v}}{V_{v}+V_{a}} \cdot \frac{\mathrm{CMRO}_{2}}{k \cdot \mathrm{CBF} \cdot[\mathrm{Hb}]} \cdot 100 \%$.

Theoretically, a greater venous blood volume $\left(V_{v}\right)$ compared with arterial blood volume $\left(V_{a}\right)$ means that the $\mathrm{rStO}_{2}$ will be closer correlated to venous blood samples from the jugular bulb than to the hemoglobin oxygen saturation of arterial blood. As this volume ratio is not known-and may vary among tissues and over time-it follows that no perfect reference standard exists. In validation studies, the "raw" $\mathrm{rStO}_{2}$ estimate-or a reference regional cerebral tissue oxygenation $\left(\mathrm{refStO} \mathrm{O}_{2} /\right.$ ref_rStO$\left.{ }_{2}\right)$ is calculated assuming a fixed ratio of venous to arterial blood-is compared with jugular venous saturation $\left(\mathrm{SjvO}_{2}\right)$ or superior vena cava saturation $\left(\mathrm{ScvO}_{2}\right)$.

\subsection{Near-Infrared Spectroscopy Instrumentation}

It is well established that the estimate of the regional tissue oxygenation, $\mathrm{rStO}_{2}$, is dependent on the instrumentation, 
e.g., differences in light source and detector distances of the sensors and different mathematical algorithms. Different commercial instruments show systematic differences in absolute values. $^{6-8}$ It is, thus, uncertain how results with a specific NIRS oximeter can be compared or combined with results obtained by other instruments. Furthermore, the repeatability of the measurements has been found to be about 5\%, meaning that repeated measurements could be about $14 \%$ points apart. ${ }^{7,9,10}$

The combination of lack of validation and poor repeatability is an important issue when designing an RCT of implementing cerebral NIRS oximetry into clinical care. The questions on what $\mathrm{rStO}_{2}$ target range to aim for, what instrument to use, and what interventions to use when $\mathrm{rStO}_{2}$ is out-of-range all need to be addressed. It is problematic if these issues are not addressed when implementing NIRS oximetry outside the rigorous settings of an RCT and, thus, the door is open for introduction of yet another intervention into standard clinical care that is poorly backed by higher level of evidence.

In the present review, we summarize the available in vivo validation of cerebral NIRS oximetry to inform future in vivo validation strategies, in particular to establish a way forward in the assessment of NIRS instrumentation for future randomized trials.

\section{Methods}

A systematic literature search was performed.

\subsection{Inclusion Criteria}

- Use of cerebral NIRS measuring regional cerebral tissue oxygenation compared with invasive measurement of central or jugular venous oxygen saturation.

- NIRS device used is commercially available and gives a measurement of saturation in percentage.

- Human studies.

- English or German language.

\subsection{Search Strategy}

The initial search on PubMed was performed combining two category searches.

The NIRS category combined the results from MeSH term "near-infrared spectroscopy" and the following keywords: "infrared spectroscopy," "NIRS," "near-infrared spectroscopy," "cerebral venous oxygenation," "near-infrared spectroscopic cerebral oxygenation," "tissue oxygenation index," "cerebral oximetry," "cerebral oximeter," and "near-infrared cerebral oximetry." The venous blood sample category combined following keywords: "superior vena cava oxygen saturation," "jugular venous oxygen saturation," "central venous oxygen saturation," "oxygenation saturation," "venous jugular bulb saturation," "mixed venous saturation," "jugular bulb oximetry."

\subsection{Subgroups}

Subgroups were defined by (1) patient group (adult or child), (2) use of cerebral NIRS device, and (3) site of venous blood sample collection or location of the continuous venous saturation catheter.
Blood samples were divided into three groups according to: site of sample collection or use of a fixed arteriovenous ratio: (1) internal jugular vein and jugular bulb $\left(\mathrm{SjOV}_{2}\right),(2)$ superior vena cava $\left(\mathrm{ScvO}_{2}\right)$, and (3) reference regional cerebral tissue oxygenation (ref_rStO 2 ).

\subsection{Data Extraction}

The following information was, where possible, extracted from the included studies:

- Patient group

- Number of patients

- Number of data points analyzed

- Mean age and range

- Mean difference between the two methods (MD), i.e., ( $\mathrm{rStO}_{2}$-cerebrovenous saturation)

- Standard deviation of the differences between the two methods (SD)

- Limits of agreement (LOA), i.e., MD +/- (2SD).

The MATLAB ${ }^{\circledR} \quad$ (MathWorks, Inc., Massachusetts) script Grabit (http://www.mathworks.com/matlabcentral/ fileexchange/7173-grabit) allows data extraction from an image file. In studies without Bland-Altman plots, we extracted data from scatter plots enabling estimation of $\mathrm{MD}, \mathrm{SD}$, and LOA.

\subsection{Statistical Analysis}

To assess the agreement between $\mathrm{rStO}_{2}$ estimated by NIRS and by blood samples, weighted averages of the MDs and SDs from each study were calculated:

$\mathrm{MD}_{\substack{\text { weighted } \\ \text { average }}}=\left(1 / \sum_{i=1}^{n} N_{i}\right) \sum_{i=1}^{n} \mathrm{MD}_{i} \cdot N_{i}$,

$\mathrm{SD}_{\substack{\text { weighted } \\ \text { average }}}=\left(1 / \sum_{i=1}^{n} N_{i}\right) \sum_{i=1}^{n} \mathrm{SD}_{i}^{2} \cdot N_{i}$,

$\mathrm{MD}_{i}, N_{i}$, and $\mathrm{SD}_{i}$ are the mean difference, number of subjects, and the standard deviation of the differences in the $i$ 'th study.

The bias between $\mathrm{rStO}_{2}$ estimated by NIRS and by blood samples was also assessed by the root mean square error, $A_{\mathrm{RMS}}$.

Furthermore, a mixed effects model for each instrument

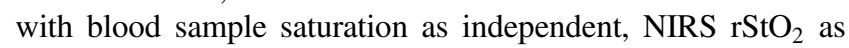
dependent, and study as random factor was created. The $95 \%$ confidence intervals of the regression coefficients were calculated by bootstrapping.

All statistical tests were done in R [R Core Team (2013). $\mathrm{R}$ : A language and environment for statistical computing. R Foundation for Statistical Computing, Vienna, Austria].

\section{Results}

\subsection{Literature Search}

The result of the initial literature search was 698 papers. The records were screened and 262 abstracts were assessed to select studies fulfilling our inclusion criteria. We identified 41 in vivo validation studies of NIRS and additional 15 studies were 
identified by manual search of cited references, resulting in 25 pediatric (age $<18$ years) and 31 adult (age $>18$ years) studies published from 1996 to 2015.

Twenty-two pediatric studies were analyzed after exclusion of three articles. These were excluded, because either a prototype NIRS device was used ${ }^{11,12}$ or the NIRS device was not described. ${ }^{13}$ Furthermore, two studies ${ }^{14,15}$ were not included in the calculation of weighted mean deviation (MD) and SD, because the type of INVOS (COVIDIEN, Mansfield, Massachusetts) device could not be determined. 28 adult studies were analyzed after the exclusion of three studies. Two studies were excluded because a prototype NIRS device was used ${ }^{16}$ and one was excluded because it was impossible to extract the data points. $^{17}$

We found studies of INVOS (Medtronic, Minneapolis, Minnesota), NIRO (Hamamatsu Photonics, Hamamatsu city, Japan), EQUANOX Cerebral Oximetry System (Nonin Medical, Inc., Plymouth, Minnesota), FORESIGHT Cerebral Oximeters (CAS Medical Systems, Branford, Connecticut), and TRS-20 (Hamamatsu Photonics, Hamamatsu city, Japan).

\subsection{Pediatric Studies}

The 22 studies included in total 776 children (range 5 to 100). The overall mean $\mathrm{ScvO}_{2}$ was $67.7 \%$ (SD 16.1\%), $\mathrm{SjvO}_{2} 70.4 \%$ (SD 13.0\%), and $\mathrm{refStO}_{2} 75.0 \%$ (SD 8.9\%). The overall MD was $-1.2 \%$ with LOA of $-12.5 \%$ to $10.1 \%$ between NIRS $\mathrm{rStO}_{2}$ and $\mathrm{refStO}_{2},-1.9 \%$ with $\mathrm{LOA}-17.8 \%$ to $14.0 \%$, and $-2.0 \%$ with $\mathrm{LOA}$ of $-21.8 \%$ to $17.6 \%$ between $\mathrm{NIRS} \mathrm{rStO}_{2}$ and $\mathrm{SjvO}_{2}$ and $\mathrm{ScvO}_{2}$, respectively (Fig. 1). The regression coefficients of the regression lines between $\mathrm{ScvO}_{2}$ (Fig. 2), $\mathrm{SjvO}_{2}$ (Fig. 3), and refStO ${ }_{2}$ (Fig. 4) against $\mathrm{rStO}_{2 \text { (NIRS) }}$ are shown in Table 1.

\subsection{Adult Studies}

The 28 studies included in total 604 participants (range 9 to 50). The overall mean $\mathrm{ScvO}_{2}$ was $77.4 \%$ (SD 10.5\%), $\mathrm{SjvO}_{2} 68.1 \%$

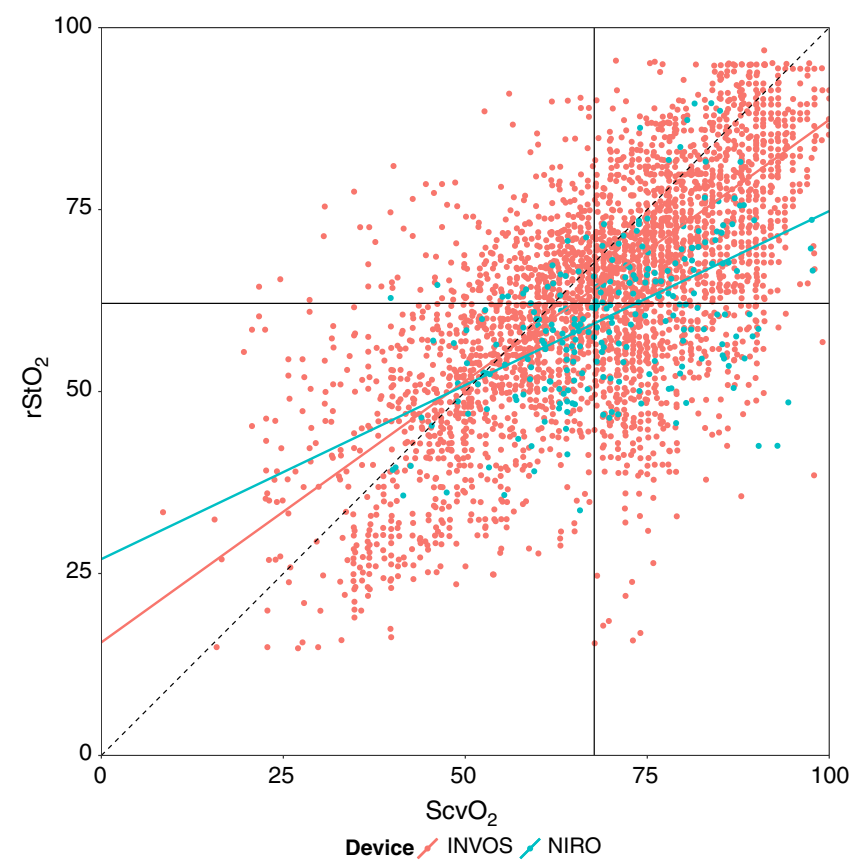

Fig. 2 NIRS $\mathrm{rStO}_{2}$ versus central venous saturation $\left(\mathrm{ScvO}_{2}\right)$ in children. The horizontal line represents the overall mean $\mathrm{rStO}_{2}$; the vertical line the mean refStO ${ }_{2}$.

(SD 15.3\%), and $\mathrm{refStO}_{2}$ 66.9\% (SD 11.5\%). NIRS $\mathrm{rStO}_{2}$ and $\mathrm{refStO}_{2}$ had an overall $\mathrm{MD}$ of $0.2 \%$ and LOA of $-13.0 \%$ to $13.4 \%$. In comparison, the MD between the $\mathrm{NIRS} \mathrm{rStO}_{2}$ and $\mathrm{SjvO}_{2}$ and $\mathrm{ScvO}_{2}$ was $-0.5 \%$ with $\mathrm{LOA}-20.7 \%$ to $19.7 \%$ and $-8.8 \%$ with LOA of $-24.1 \%$ to $6.5 \%$, respectively (Fig. 5). The regression coefficients of the regression lines between $\mathrm{ScvO}_{2}$ (Fig. 6), $\mathrm{SjvO}_{2}$ (Fig. 7), and ref_StO (Fig. 8) against $\mathrm{rStO}_{2 \text { (NIRS) }}$ are shown in Table 2.

All included studies are presented in subgroups in Table 3. The table shows the number of subjects in each study and,

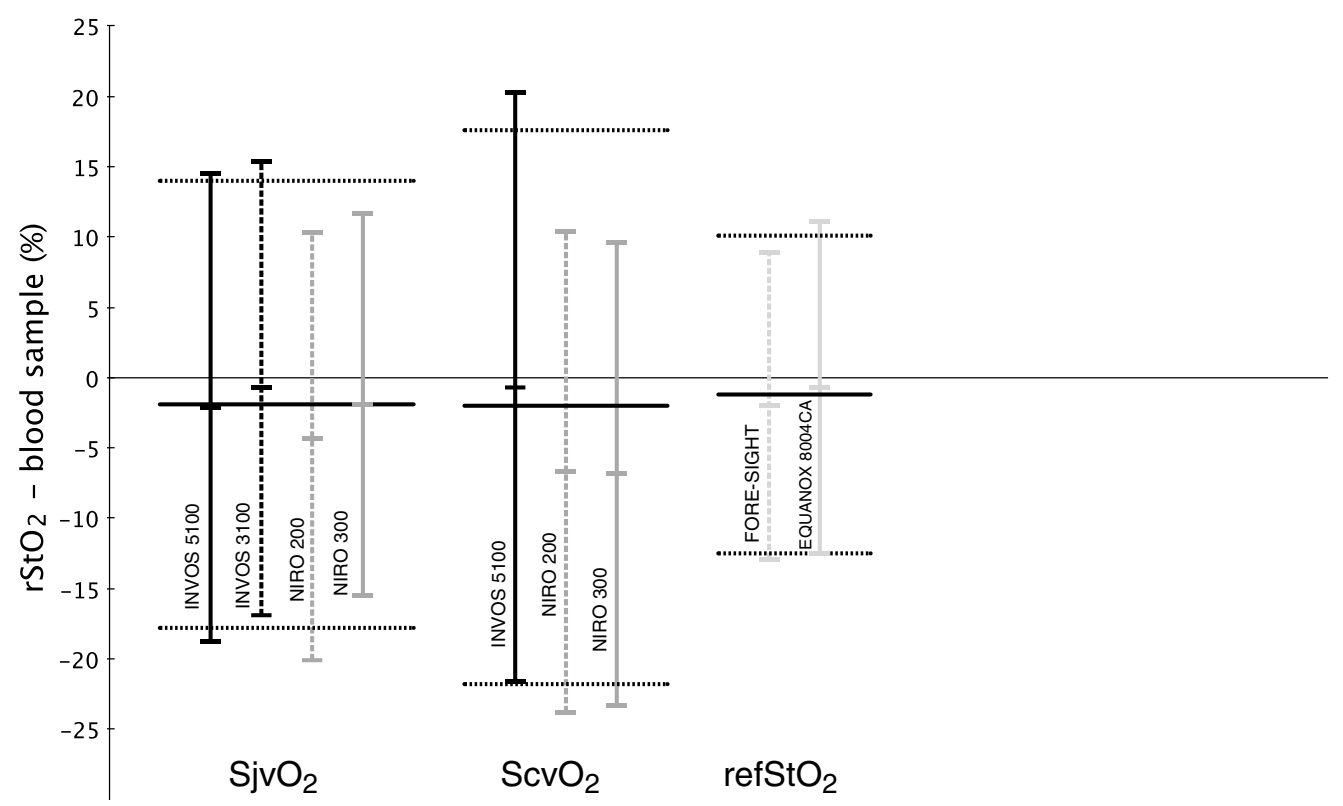

Fig. 1 Pediatric studies; MD and associated LOA between refStO $\mathrm{S}_{2}, \mathrm{SjvO}_{2}, \mathrm{ScvO}_{2}$, and $\mathrm{NIRS} \mathrm{rStO}_{2}$ within the different groups. Weighted MD and LOA are also shown. 


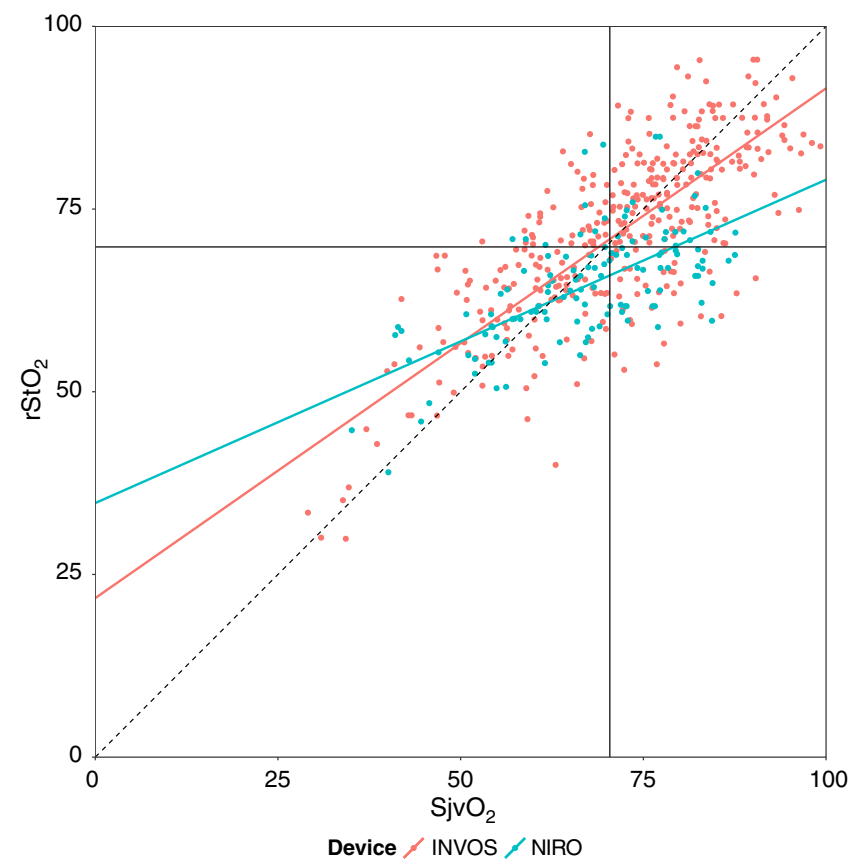

Fig. $3 \mathrm{NIRS} \quad \mathrm{rStO}_{2}$ versus jugular venous saturation $\left(\mathrm{SjvO}_{2}\right)$ in children. The horizontal line represents the overall mean $\mathrm{rStO}_{2}$; the vertical line represents the mean refStO ${ }_{2}$.

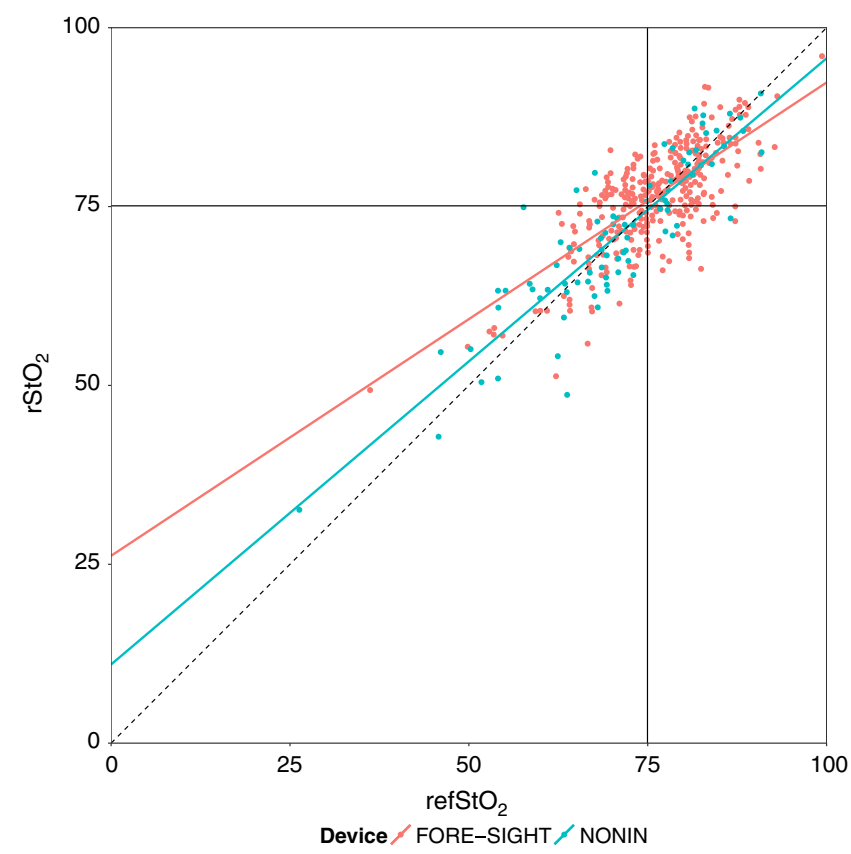

Fig. $4 \mathrm{NIRS} \mathrm{rStO}_{2}$ versus reference saturation $\left(\mathrm{refStO}_{2}\right)$ in children. The horizontal line represents the overall mean $\mathrm{rStO}_{2}$; the vertical line represents the mean refStO.

if available, the number of datapoints. Furthermore, MD, precision, and $A_{\mathrm{RMS}}$ are shown for each study. The consistency between original results and results obtained by Grabit was assessed by calculating MD of the differences between original MD's and those obtained by Grabit. We found a MD of $0.09 \%$ (SD $0.34 \%$ ).

\section{Discussion}

\subsection{Principal Findings}

We found that although the NIRS $\mathrm{rStO}_{2}$ most closely estimates a weighted average of arterial and venous blood $\left(\right.$ refStO ${ }_{2} /$ ref_rStO $\left.{ }_{2}\right)$ in both adults and children, the agreement is poor with LOA of more than $+/-13 \%$ in both populations. Moreover, we found that irrespective of whether venous blood was drawn from the central circulation or from the jugular bulb, or the theoretical arterial component was accounted for, NIRS $\mathrm{rStO}_{2}$ was increasingly overestimating blood saturation in the low ranges, i.e., $\mathrm{NIRS} \mathrm{rStO}_{2}$ has oxygen-level dependent bias. We found no clear systematic differences between the different instruments.

\subsection{Appraisal of Our Data Analysis Methods}

We believe that this is the most exhaustive review of the literature on NIRS validation yet.

We utilized a MATLAB script "Grabit" enabling us to incorporate data from almost all published work. The use of Grabit, however, has limitations. The quality of scaling and calibration of the axes depend on how clearly the values of the axes in the original linear plot are specified, and extracting data from a scatter plot with many and clustered data points may introduce errors. Data points with the greatest distance from the linear regression line are typically the easiest to discriminate, whereas clustered data points may be overlooked. This may affect the Bland-Altman analysis. To assess this possible problem, we compared the original MD with the MD calculated with data retrieved with Grabit and found good consistency with an overall difference of $0.09 \%$ (SD 0.34\%). Another problem when using data of this nature is that several data points may be from the same study participant. This is very rarely indicated in the plot and therefore not accounted for in the statistical analysis.

When repeated measurements are ignored, the estimated variance will be biased toward zero. We, therefore, chose to perform simple regressions ignoring the potential errors on the measurement of blood samples and to illustrate the regressions with conventional $X-Y$ plots, although overall, these weaknesses make it unreasonable to attempt any formal statistical comparison among instruments. The review has revealed that the statistical analyses in many studies are less than perfect. There is, in our opinion, not a single clearly superior statistical method, and the most important issue might be that the study design is appropriate, i.e., data that enable estimation of the precision of each method and any level-dependent bias. The Bland-Altman analysis is appealing due to its simplicity, but often differences in precision between methods and leveldependent bias are neglected.

\subsection{Validation with Blood Samples}

We found only minor MDs between the NIRS $\mathrm{rStO}_{2}$ and the reference methods (Figs. 1 and 5), which was surprising as the reference that takes the arterial blood contribution into account must by nature be higher than the simple venous references.

Furthermore, it is obvious from the wide LOA and by look-

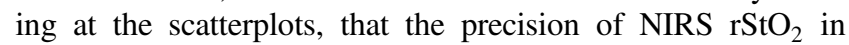
estimating venous blood saturation is poor. It is also clear that 
Table 1 Pediatric studies, regression between $\mathrm{ScvO}_{2}, \mathrm{SjvO}_{2}$, refStO

\begin{tabular}{|c|c|c|c|c|c|c|}
\hline & \multicolumn{2}{|c|}{$\mathrm{ScvO}_{2}$} & \multicolumn{2}{|c|}{$\mathrm{SjvO}_{2}$} & \multicolumn{2}{|c|}{$\mathrm{RefStO}_{2}$} \\
\hline & Slope $(95 \% \mathrm{Cl})$ & Intercept $(95 \% \mathrm{Cl})$ & Slope $(95 \% \mathrm{Cl})$ & Intercept $(95 \% \mathrm{Cl})$ & Slope $(95 \% \mathrm{Cl})$ & Intercept $(95 \% \mathrm{Cl})$ \\
\hline INVOS & $0.71(0.59 ; 0.0 .85)$ & $15.5(6.7 ; 24.5)$ & $0.70(0.51 ; 0.86)$ & $21.8(9.1 ; 35.4)$ & NA & NA \\
\hline NONIN & NA & NA & NA & NA & $0.85(0.75 ; 0.95)$ & $11.0(3.9 ; 18.1)$ \\
\hline NIRO & $0.48(0.29 ; 0.67)$ & $27.0(15.7 ; 37.5)$ & $0.44(0.33 ; 0.57)$ & $34.8(27.1 ; 42.1)$ & NA & NA \\
\hline FORE-SIGHT & NA & NA & NA & NA) & $0.66(0.55 ; 0.77)$ & $26.2(16.0 ; 35.7)$ \\
\hline
\end{tabular}

NA: Data not available in studies.

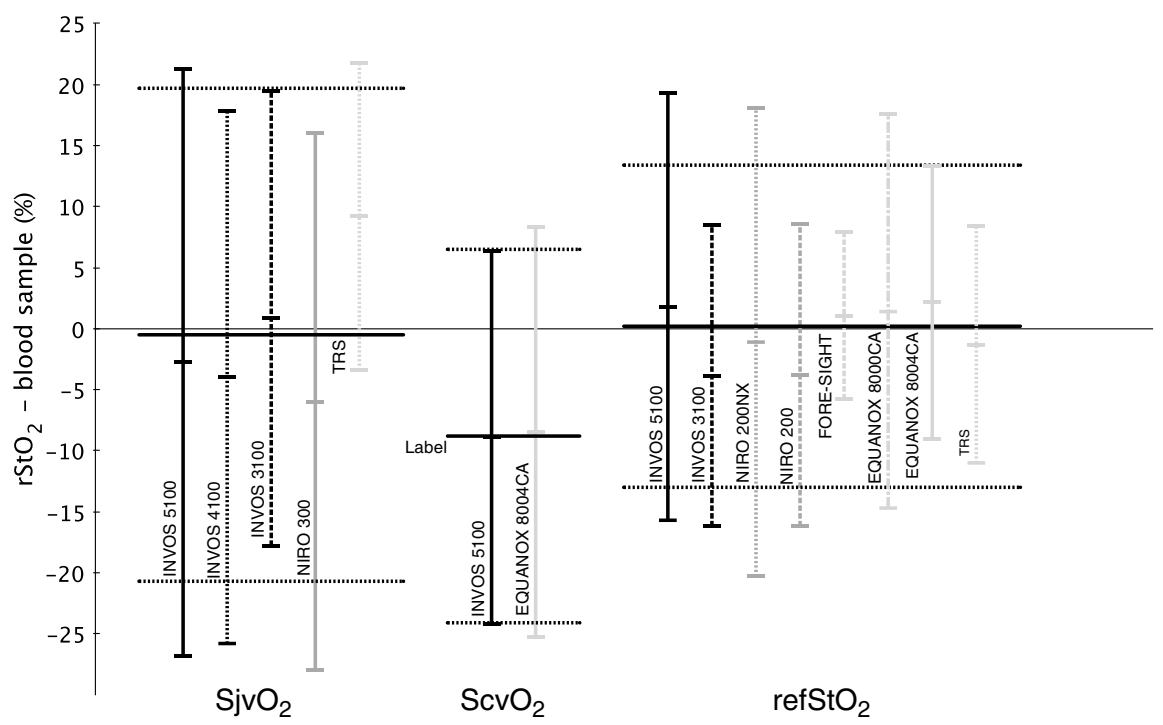

Fig. 5 Adult studies; MD and associated LOA between refStO $, \mathrm{SjvO}_{2}, \mathrm{ScvO}_{2}$, and $\mathrm{NIRS} \mathrm{rStO}_{2}$ within the different groups. Weighted MD and LOA are also shown.

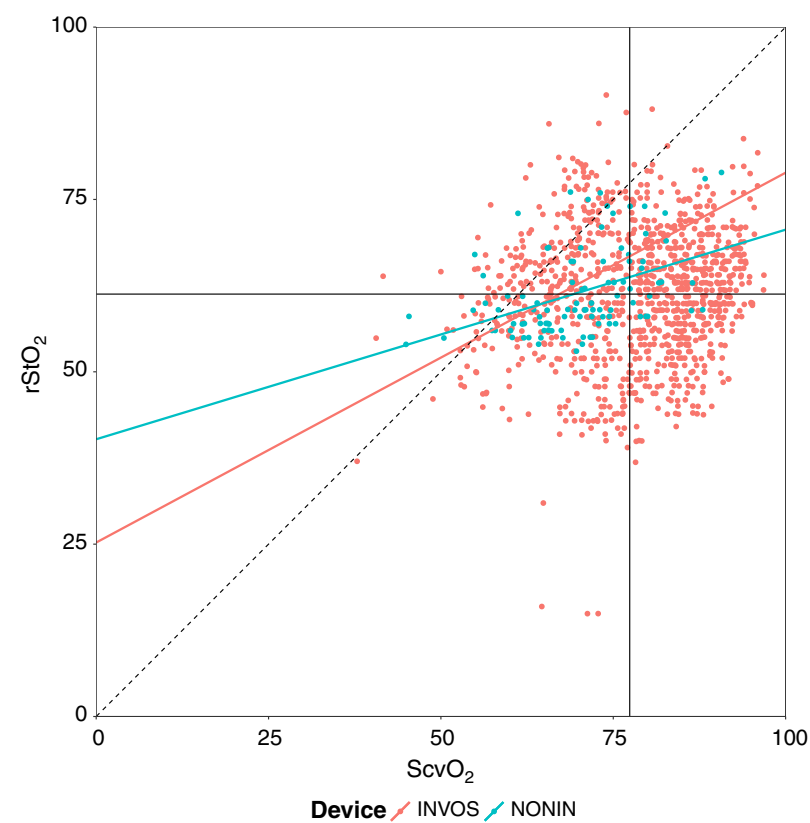

Fig. $6 \mathrm{NIRS} \mathrm{rStO}_{2}$ versus central venous saturation $\mathrm{ScvO}_{2}$ in adults. The horizontal line represents the overall mean $\mathrm{rStO}_{2}$; the vertical line represents the mean $\mathrm{ScvO}_{2}$.

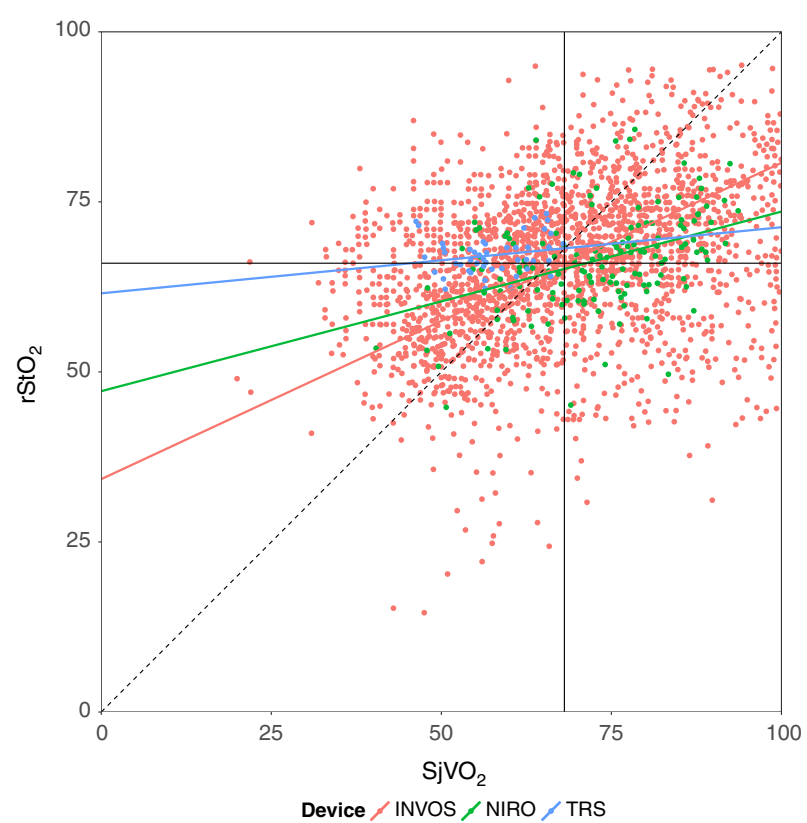

Fig. $7 \mathrm{NIRS} \mathrm{rStO}_{2}$ versus jugular venous saturation $\left(\mathrm{SjvO}_{2}\right)$ in adults. The horizontal line represents the overall mean $\mathrm{rStO}_{2}$; the vertical line represents the mean $\mathrm{SjvO}_{2}$. 


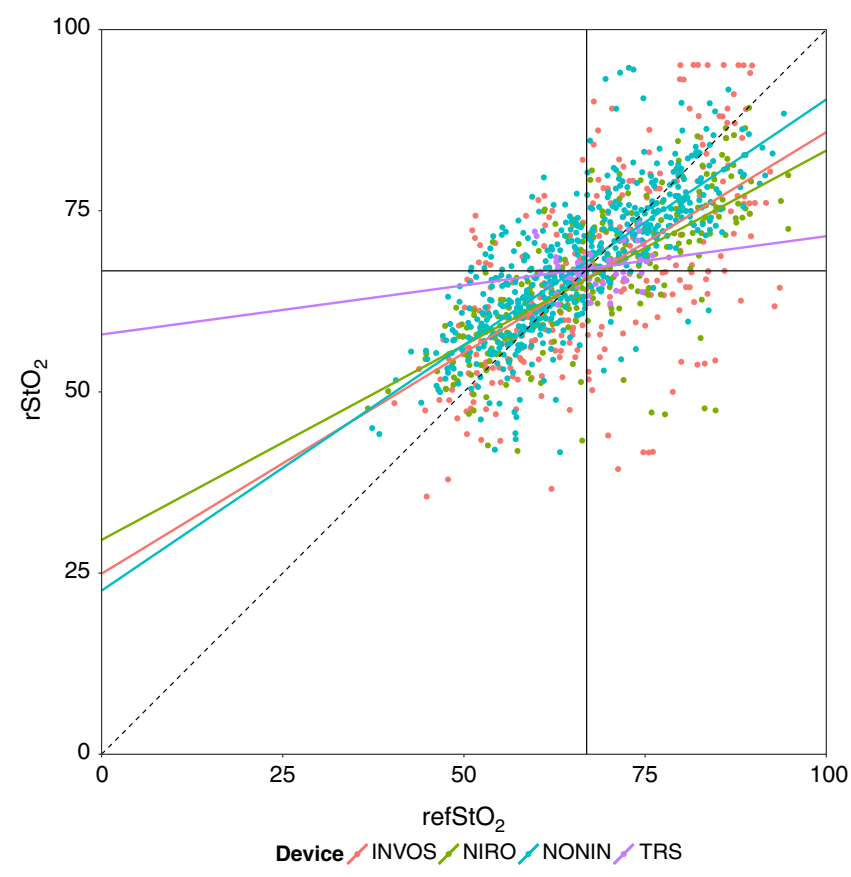

Fig. $8 \mathrm{NIRS} \mathrm{rStO}_{2}$ versus reference saturation $\left(\mathrm{refStO}_{2}\right)$ in adults. The horizontal line represents the overall mean $\mathrm{rStO}_{2}$; the vertical line represents the mean refStO ${ }_{2}$.

NIRS $\mathrm{rStO}_{2}$, irrespective of instrument, has an oxygenation level-dependent bias, i.e., the difference between $\mathrm{rStO}_{2}$ and venous saturation changes with de- and increasing average of saturation.

When the agreement between methods varies with the level of the measured, the difference between the methods should be regressed on the average of the two methods. LOA is then calculated from the residual SD from the regression. ${ }^{65}$ Failing to do so will result in the LOA being too wide. Unfortunately, the appropriate statistical analysis has seldom been applied even in the studies with very obvious level-dependent bias. ${ }^{20,28,31,33,38,44,46,52,59}$

The poor precision of the NIRS estimates is strikingly consistent throughout the studies. An explanation could be that NIRS is an estimate of the local tissue oxygenation, whereas the blood samples represent regional oxygenation. It has been suggested that jugular bulb oximetry is in fact insensitive to regional ischemia due to "flow-weighting"; 66 however, none of the included studies deal with procedures or patients that are in particular risk of local ischemia.
Another explanation could be that systematic differences between different regions of the brain would translate into variable agreement depending on a sensor position. However, there are no data suggesting that different regions of the brain are systematically oxygenated differently. ${ }^{67,68}$ Sørensen et al. ${ }^{69}$ examined the effect of skin oxygen saturation and found that whole body heating and administration of norepinephrine affected $\mathrm{rStO}_{2}$, whereas $\mathrm{SjvO}_{2}$ remained unchanged. This suggests that local fluctuations in skin saturation may contribute to variations in the $\mathrm{SjO}_{2} \mathrm{rStO}_{2}$ agreement. In that regard, it is also likely that skin pigmentation influences the NIRS signal as has been well documented being the case with both pulse oximetry ${ }^{70,71}$ and NIRS. ${ }^{8}$ Unfortunately, the included studies provide very little information on individual skin pigmentation.

Theoretically, it would thus be expected that the pediatric studies would reveal better accuracy and precision as the skin is thinner and the sensor-to-cortex distance is shorter. Theoretical modeling and clinical data show that the average depth of penetration of NIR light is directly proportional to the separation of the emitting and receiving optodes. ${ }^{72}$ However, the signal will decrease as the light travels longer in. The separation is the same on the pediatric/neonatal and adult sensors on INVOS and NIRO, whereas NONIN and FORE-SIGHT have shorter distance on the pediatric/neonatal sensors. In both the pediatric and the adult studies, the agreement between NIRS and refStO2 was best with MD $1.2 \%$ (LOA of $-12.5 \%$ to $10.1 \%$ ) in children and $0.2 \%$ (LOA $-13.0 \%$ to $13.4 \%$ ) in adults, but the results do not support the notion that NIRS is better suited for the pediatric population as the LOA are quite similar throughout (Figs. 1 and 5).

As pointed out by Bland and Altman, ${ }^{65}$ lack of repeatability can interfere with the comparison of two methods. If one method has poor repeatability, the agreement between the two methods is bound to be poor. The repeatability of different NIRS monitors has been examined. Hyttel-Sorensen et al. ${ }^{10}$ found repeatability ranging from $2.0 \%$ to $5.4 \%$ (within subject $\mathrm{SD}$ ) with various instruments, whereas in another study comparing INVOS 5100, NONIN-EQUANOX 8004CA, and FORESIGHT, $S_{w}$ was $2.9,4.9$, and 2.0 , respectively. ${ }^{7}$ Hessel et al. $^{73}$ found a $S_{w}$ of 4.8 with INVOS 5100 and 2.8 with FORESIGHT. This level of repeatability may be the single most important factor in the poor ability of NIRS to estimate the blood sample saturations.

There are several drawbacks when using blood samples to validate NIRS. First, the reflected NIRS signal is influenced by both the venous, capillary, and arterial blood. It is uncertain how much each vascular bed contributes to the overall light

Table 2 Adult studies, regression between $\mathrm{ScvO}_{2}, \mathrm{SjvO}_{2}$, refStO ${ }_{2}$, and $\mathrm{rStO}_{2}$.

\begin{tabular}{|c|c|c|c|c|c|c|}
\hline & \multicolumn{2}{|c|}{$\mathrm{ScvO}_{2}$} & \multicolumn{2}{|c|}{$\mathrm{SjvO}_{2}$} & \multicolumn{2}{|c|}{$\mathrm{RefStO}_{2}$} \\
\hline & Slope $(95 \% \mathrm{Cl})$ & Intercept $(95 \% \mathrm{Cl})$ & Slope $(95 \% \mathrm{Cl})$ & Intercept $(95 \% \mathrm{Cl})$ & Slope $(95 \% \mathrm{Cl})$ & Intercept $(95 \% \mathrm{Cl})$ \\
\hline INVOS & $0.54(0.22 ; 0.88)$ & $25.2(2.9 ; 47.8)$ & $0.47(0.27 ; 0.63)$ & $34.2(22.5 ; 47.4)$ & $0.61(0.43 ; 0.78)$ & $24.9(13.9 ; 36.7)$ \\
\hline NONIN & $0.30(0.17 ; 0.43)$ & $40.2(31.1 ; 49.4)$ & NA & NA & $0.68(0.54 ; 0.82)$ & $22.6(13.7 ; 31.3)$ \\
\hline NIRO & NA & NA & $0.26(0.17 ; 0.36)$ & $47.2(40.3 ; 53.8)$ & $0.54(0.37 ; 0.71)$ & $29.6(20.1 ; 38.6)$ \\
\hline TRS & NA & NA & $0.10(-0.04 ; 0.24)$ & $61.6(53.5 ; 69.6)$ & $0.14(-0.05 ; 0.32)$ & $57.9(45.3 ; 70.5)$ \\
\hline
\end{tabular}

NA: Data not available in studies. 
Table 3 All included studies divided into subgroups.

Pediatric studies comparing INVOS with SVC saturation

\begin{tabular}{|c|c|c|c|c|c|c|}
\hline Study & Subjects & Data-points & Version/sensor & $\mathrm{MD}\left(\mathrm{rStO}_{2}-\mathrm{ScvO}_{2}\right)$ & Precision & ARMS \\
\hline Ricci et al. ${ }^{18}$ & 100 & 890 & $5100 /$ neonatal & 0.05 & 25.0 & 10.3 \\
\hline McQuillen et al. ${ }^{19, a}$ & 70 & NA & 5100/pediatric & -1.0 & 24.6 & NA \\
\hline Nagdyman et al. ${ }^{20}$ & 30 & 37 & 5100/pediatric & 5.6 & 7.8 & 7.1 \\
\hline Tortoriello et al. ${ }^{21, b}$ & 20 & 100 & 5100/pediatric & 3.3 & 16.6 & 9 \\
\hline Knirsch et al. ${ }^{22}$ & 60 & 120 & 5100/pediatric + adult & 0.2 & 15.7 & 8 \\
\hline Hansen et al. ${ }^{23}$ & 32 & NA & $5100 / \mathrm{NA}$ & 1.0 & 18.9 & 10.1 \\
\hline Bhutta et al. ${ }^{24, c, d, e}$ & 29 & 52 & $5100 / \mathrm{NA}$ & -2.8 & 15.0 & 8 \\
\hline Moreno et al. ${ }^{25, f}$ & 23 & 980 & $5100 / \mathrm{NA}$ & -10.5 & 27.7 & 18.4 \\
\hline Ranucci et al. ${ }^{14, f}$ & 15 & 117 & NA/NA & -5.6 & 20.8 & 11.9 \\
\hline Cua et al.26, ,f,g & 7 & 786 & $5100 / \mathrm{NA}$ & -9.2 & 17.6 & 12.7 \\
\hline Kirshbom et al. ${ }^{15, c}$ & 20 & 20 & NA/NA & -1.2 & 15.3 & 7.8 \\
\hline Ginther et al. ${ }^{27, c, f}$ & 8 & 690 & $5100 / \mathrm{NA}$ & -9.4 & 15.8 & 12.3 \\
\hline \multicolumn{7}{|c|}{ Pediatric studies comparing INVOS with JB saturation } \\
\hline Study & Subjects & Data-points & Version/sensor & $\mathrm{MD}\left(\mathrm{rStO}_{2}-\mathrm{SjvO}_{2}\right)$ & Precision & $A_{\mathrm{RMS}}$ \\
\hline Knirsch et al. ${ }^{22}$ & 60 & 120 & 5100/pediatric + adult & -0.6 & 18.0 & 9.1 \\
\hline Nagdyman et al..$^{20}$ & 30 & 61 & $5100 /$ pediatric & -5.2 & 13.6 & 8.4 \\
\hline Daubeney et al. ${ }^{28, \mathrm{~h}}$ & 40 & 147 & $3100 / \mathrm{NA}$ & -0.7 & 20.2 & 10 \\
\hline Abdul-Khaliq et al. ${ }^{29, c}$ & 30 & 30 & $3100 / \mathrm{NA}$ & -0.8 & 8.1 & 4.1 \\
\hline \multicolumn{7}{|c|}{ Pediatric studies comparing NIRO with SVC saturation } \\
\hline Study & Subjects & Data-points & Version & $\mathrm{MD}\left(\mathrm{rStO}_{2}-\mathrm{ScvO}_{2}\right)$ & Precision & $A_{\mathrm{RMS}}$ \\
\hline Nagdyman et al..$^{20, h}$ & 30 & 36 & 200 & -4.9 & 15.2 & 9.3 \\
\hline Redlin et al. ${ }^{30, \mathrm{c}, \mathrm{e}}$ & 20 & 55 & 200 & -9.4 & 19.6 & 13.7 \\
\hline Weiss et al. ${ }^{31, \mathrm{c}, \mathrm{h}, \mathrm{e}}$ & 28 & 85 & 300 & -8.9 & 13 & 11.2 \\
\hline Nagdyman et al. ${ }^{32, \mathrm{c}, \mathrm{g}}$ & 43 & 70 & 300 & -5.5 & 18.4 & 10.8 \\
\hline \multicolumn{7}{|c|}{ Pediatric studies comparing NIRO with JB saturation } \\
\hline Study & Subjects & Data-points & Version & $\mathrm{MD}\left(\mathrm{rStO}_{2}-\mathrm{SvjO}_{2}\right)$ & Precision & $A_{\mathrm{RMS}}$ \\
\hline Nagdyman et al. ${ }^{20, h}$ & 30 & 60 & 200 & -4.3 & 20.0 & 11.1 \\
\hline Nagdyman et al. ${ }^{33, \mathrm{~h}}$ & 60 & 60 & 300 & -1.8 & 13.5 & 7.1 \\
\hline Shimizu et al. ${ }^{34}$ & 5 & 5 & 300 & -3.4 & 14.4 & 7.7 \\
\hline \multicolumn{7}{|c|}{ Pediatric studies comparing NONIN EQUANOX with ref_rStO 2 saturation } \\
\hline Study & Subjects & Data-points & Sensor & $\mathrm{MD}\left(\mathrm{rStO}_{2}\right.$ - ref_rStO $\left.{ }_{2}\right)$ & Precision & $A_{\mathrm{RMS}}$ \\
\hline Kreeger et al.35,i & 86 & 86 & 8004CB & -0.7 & 11.7 & 5.4 \\
\hline
\end{tabular}


Table 3 (Continued).

\begin{tabular}{|c|c|c|c|c|c|c|}
\hline \multicolumn{7}{|c|}{ Pediatric studies comparing FORE-SIGHT with ref_rStO ${ }_{2}$ saturation } \\
\hline Study & Subjects & Data-points & Sensor & $\mathrm{MD}\left(\mathrm{rStO}_{2}-\right.$ ref_rStO $\left.{ }_{2}\right)$ & Precision & $A_{\mathrm{RMS}}$ \\
\hline Kussmann et al..$^{36}$ & 40 & 218 & Pediatric & -2.6 & 11.1 & 5.4 \\
\hline Rais-Bahrami et al. ${ }^{37, \mathrm{j}}$ & 10 & 225 & Neonatal & 0.4 & 10.2 & 5.2 \\
\hline \multicolumn{7}{|c|}{ Adult studies comparing INVOS with JB saturation } \\
\hline Study & Subjects & Data-points & Version/sensor & $\mathrm{MD}\left(\mathrm{rStO}_{2}-\mathrm{SjvO}_{2}\right)$ & Precision & $A_{\mathrm{RMS}}$ \\
\hline Jeong et al. ${ }^{38, \mathrm{fth}}$ & 40 & 726 & 5100/adult & 7.2 & 31.0 & 17.8 \\
\hline Choi et al. ${ }^{39, c, f, k}$ & 35 & 140 & 5100/adult & -9.5 & 13.6 & 11.7 \\
\hline Colquhoun et al. ${ }^{40,1}$ & 20 & NA & 5100/adult & -10.8 & 22.3 & 15.9 \\
\hline Kim et al. ${ }^{41, m, n}$ & 42 & NA & 4100/adult & 3.9 & 13.8 & 8.1 \\
\hline Leyvi et al. ${ }^{42}$ & 29 & NA & 4100/adult & -15.4 & 29.8 & 23.3 \\
\hline Henson et al. ${ }^{43,0}$ & 30 & NA & 3100/adult & 3.8 & 17.8 & 10.1 \\
\hline Buunk et al. ${ }^{44, h, f}$ & 10 & 179 & 3100/adult & -4 & 19.8 & 11.3 \\
\hline Lewis et al. ${ }^{45, f}$ & 10 & NA & 3100/adult & 4 & 17.4 & NA \\
\hline Grubhofer et al. ${ }^{46, c}$ & 12 & NA & 3100/adult & -5.5 & 18.1 & 10.6 \\
\hline Minassian et al. ${ }^{47, c, p}$ & 9 & NA & 3100/adult & 1.6 & 21.9 & 11.1 \\
\hline \multicolumn{7}{|c|}{ Adult studies comparing INVOS with refStO ${ }_{2}$ saturation } \\
\hline Study & Subjects & Data-points & Version/sensor & $\mathrm{MD}\left(\mathrm{rStO}_{2}-\mathrm{refStO}_{2}\right)$ & Precision & $A_{\mathrm{RMS}}$ \\
\hline Bickler et al. ${ }^{8, q}$ & 23 & 352 & $5100 /$ adult & 0.1 & 19.4 & 9.8 \\
\hline Rasmussen et al. ${ }^{48, r}$ & 11 & NA & 5100/adult & 5.5 & 12.6 & 8.6 \\
\hline Grubhofer et al. ${ }^{46, \mathrm{~h}}$ & 12 & 67 & 3100/adult & -13.0 & 14.0 & 15.1 \\
\hline Pollard et al. ${ }^{49, \mathrm{~s}}$ & 10 & NA & 3100/adult & 2.3 & 10.4 & NA \\
\hline Pollard et al. ${ }^{50, t, u}$ & 16 & NA & 3100/adult & -0.9 & 12.2 & NA \\
\hline \multicolumn{7}{|c|}{ Adult studies comparing INVOS with $\mathrm{ScVO}_{2}$ saturation } \\
\hline Study & Subjects & Data-points & Version/sensor & $\mathrm{MD}\left(\mathrm{rStO}_{2}-\mathrm{ScVO}_{2}\right)$ & Precision & $A_{\mathrm{RMS}}$ \\
\hline Dullenkopf et al. ${ }^{51, c, v}$ & 34 & 172 & 5100/adult & -1.5 & 15.8 & 8.1 \\
\hline Schön et al.52,c,d,h,v & 26 & 52 & 5100/adult & 2.2 & 12.5 & 6.6 \\
\hline Harilall et al. ${ }^{53, c}$ & 20 & NA & 5100/adult & -25.3 & 15.3 & 26.5 \\
\hline Paarmann et al. ${ }^{54, f, v}$ & 20 & NA & 5100/adult & -5.8 & 12.6 & 8.9 \\
\hline Lichtenstern et al. ${ }^{55, \mathrm{c}}$ & 16 & NA & 5100/adult & -13.2 & 18.2 & 16.2 \\
\hline Baraka et al. ${ }^{56, c, f, v}$ & 14 & 27 & 5100/adult & -16.3 & 25.8 & 21 \\
\hline Paarmann et al. ${ }^{57, f, v}$ & 10 & 250 & 5100/adult & -2.4 & 11.4 & 3.5 \\
\hline Koch et al. ${ }^{58, \mathrm{c}}$ & 50 & 115 & 5100/adult & -12.3 & 12.8 & 17.7 \\
\hline \multicolumn{7}{|c|}{ Adult studies comparing NIRO with JB saturation } \\
\hline Study & Subjects & Data-points & Version & $\mathrm{MD}\left(\mathrm{rStO}_{2}-\mathrm{SjvO}_{2}\right)$ & Precision & $A_{\mathrm{RMS}}$ \\
\hline Ali et al. ${ }^{59, \mathrm{~h}}$ & 17 & 118 & 300 & -6.7 & 21.4 & 13.1 \\
\hline Yamashita et al. ${ }^{60, c}$ & 10 & 40 & 300 & -4.9 & 23 & 12.5 \\
\hline
\end{tabular}


Table 3 (Continued).

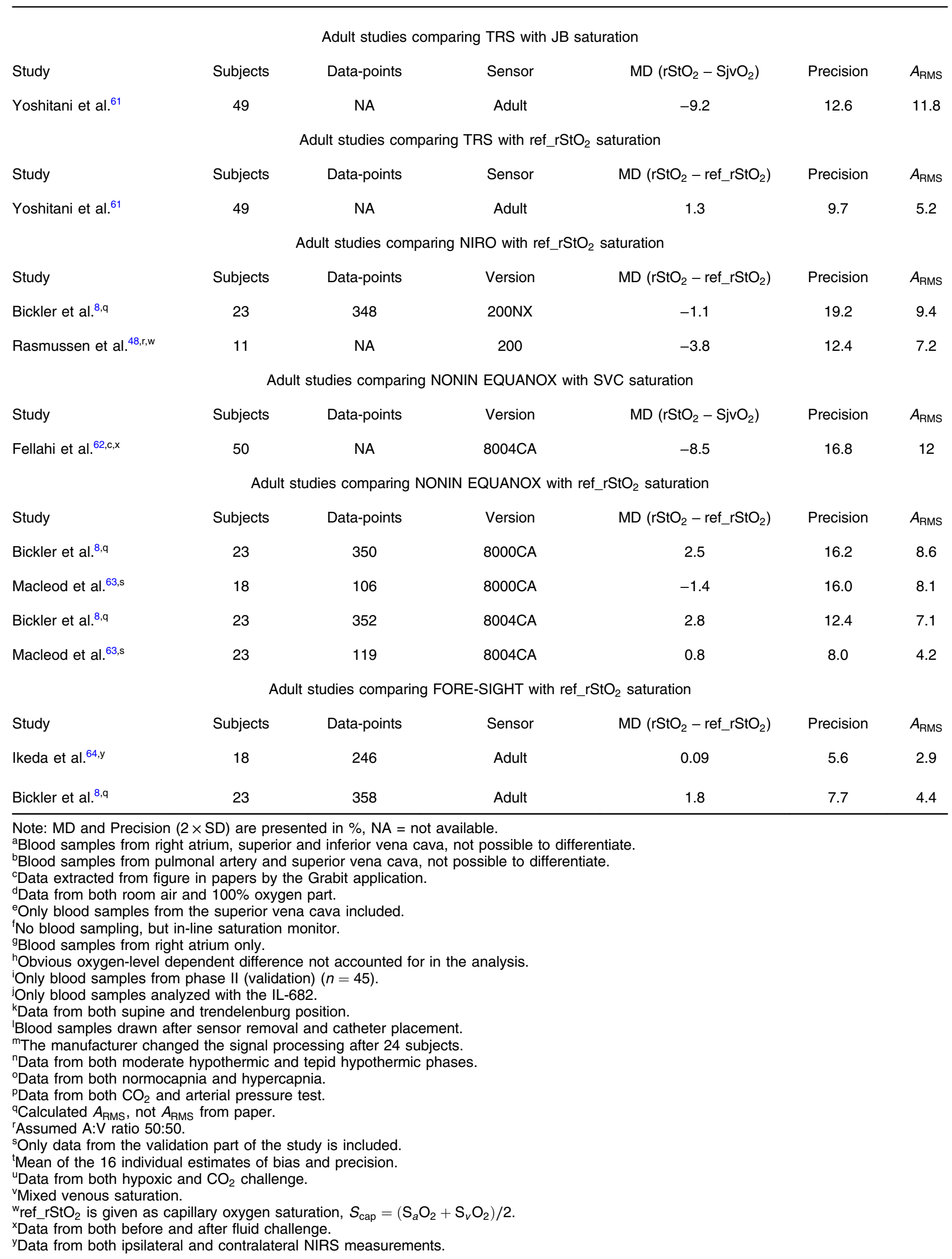


attenuation, i.e., the volume ratio could be different between subjects and within subjects over time. Ito et al. showed that with changes in $\mathrm{PaCO}_{2}$ (partial pressure of carbon dioxide in arterial blood), the arterial blood volume followed changes in cerebral blood volume. The same was not observed in the case of the capillary or venous blood volume (29). It is notable that the commercial instruments assume different A:V (arteriovenous) ratios and likely are calibrated against different references. Second, the contribution of extra-cerebral tissue to both the NIRS signal and blood samples is likely not similar. ${ }^{20}$ Third, it has been shown that the rate of withdrawal influences the jugular venous saturation, resulting in higher saturation with faster withdrawal. ${ }^{74}$ Use of continuous saturation monitors might be a potential solution to decrease such error, but when looking at studies using in-line saturation monitors, ${ }^{14,25-27}$ greater negative bias is found.

Fourth, it is not really possible to draw blood from the jugular bulb or superior vena cava in preterm infants. Our search identified two studies that used a neonatal sensor, but neither of the studies included neonates. This reflects a major challenge because the neonatal population is in many regards the most likely to benefit from cerebral NIRS monitoring as no other modality has been approved to provide continuous estimation of blood flow in neonates. Furthermore, the short distance from skin to cerebral cortex is ideal for NIRS measurements. It is thus not surprising that NIRS is increasingly used in the neonatal intensive care, but validation in this population must be done by other methods than what used in older patient groups.

\subsection{Future Near-Infrared Spectroscopy Validation}

It is remarkable that despite this rather large dataset, we are unable to draw firm conclusions. A group under International Organization for Standardization is currently working on a guideline for NIRS validation. Looking at the heterogeneity of the study results presented here, it would be a step forward to have some common framework for future validation. From our review, it would seem appropriate to recommend a statistical analysis. It would make comparison of study results more straightforward. It could also guide the design of the studies. Many studies lack estimation of precision/repeatability and future studies should aim at deciphering the different levels of variation in the NIRS versus blood sample relationship.

A different approach is using a liquid blood lipid phantom. ${ }^{75-77}$ This is inspired by the work of Suzuki et al. ${ }^{78}$ that validated the NIRO system in a blood lipid phantom with oxygen consuming yeast to drive the oxygenation down. This model has the advantage that the oxygenation can be changed from $100 \%$ to close to zero. Moreover with a liquid phantom, it is possible to establish a reference saturation by either co-oximetry, ${ }^{78}$ measurements of $\mathrm{pO}_{2}$ (partial pressure of oxygen), $\mathrm{pCO}_{2}$ (partial pressure of carbon dioxide), $\mathrm{pH}$ and calculate an estimate of saturation, or other optical methods. ${ }^{75,77}$ It is possible to create different combinations of scattering and absorption properties by altering the content of lipid and hemoglobin. Lastly, a layered design can be implemented by having the sensors placed on solid windows with known optical properties. The method allows validation of the neonatal sensors, which cannot be tested by blood sampling, but many aspects still need to be resolved for it to be more broadly implemented. First of all, the optical properties must be defined and some common guideline for the construction of the phantom for each relevant population (neonatal, pediatric, and adult) should be made. It also needs more robust comparison with clinical NIRS testing before it can be an alternative to the traditional validation by blood sampling.

\section{Conclusion}

In this overview of in vivo validation of cerebral NIRS in pediatric and adult patients, we found a fair agreement between the overall mean cerebral tissue oxygenation and the mean of a reference value measured by co-oximetry whatever NIRS instrument or site of blood sampling used. Cerebral oxygenation overestimated the reference at low values, some instruments apparently more than others. Thus, a high degree of scatter and a lack of a good reference method complicate in vivo validation of NIRS.

It is difficult to draw any firm conclusions despite the large number of studies, and the result of this review leaves us questioning if more of such validation studies of cerebral NIRS oximetry are really needed or if it is time for different approaches.

\section{Disclosures}

The authors declare that there are no conflicts of interest related to this article.

\section{References}

1. A. Deschamps et al., "Reversal of decreases in cerebral saturation in high-risk cardiac surgery," J. Cardiothorac. Vasc. Anesth. 27, 12601266 (2013).

2. J. M. Murkin et al., "Monitoring brain oxygen saturation during coronary bypass surgery: a randomized, prospective study," Anesth. Analg. 104, 51-58 (2007).

3. S. Hyttel-Sørensen et al., "Cerebral near infrared spectroscopy oximetry in extremely preterm infants: phase II randomised clinical trial," $B M J$ 350, g7635-g7635 (2015).

4. A. Pellicer et al., "The SafeBoosC phase II randomised clinical trial: a treatment guideline for targeted near-infrared-derived cerebral tissue oxygenation versus standard treatment in extremely preterm infants," Neonatology 104, 171-178 (2013).

5. I. Tachtsidis et al., "Measurement of cerebral tissue oxygenation in young healthy volunteers during acetazolamide provocation: a transcranial Doppler and near-infrared spectroscopy investigation," in Oxygen Transport to Tissue XXIX, K. A. Kang, D. K. Harrison, and D. F. Bruley, Eds., Advances in Experimental Medicine and Biology, Vol. 614, pp. 389-396, Springer, Boston, Massachusetts, (2008).

6. A. Dullenkopf et al., "Measurement of cerebral oxygenation state in anaesthetized children using the INVOS 5100 cerebral oximeter," Pediatr. Anesth. 13, 384-391 (2003).

7. S. Hyttel-Sørensen, T. W. Hessel, and G. Greisen, "Peripheral tissue oximetry: comparing three commercial near-infrared spectroscopy oximeters on the forearm," J. Clin. Monit. Comput. 28, 149-155 (2014).

8. P. E. Bickler, J. R. Feiner, and M. D. Rollins, "Factors affecting the performance of 5 cerebral oximeters during hypoxia in healthy volunteers," Anesth. Analg. 117, 813-823 (2013).

9. A. Dullenkopf et al., "Reproducibility of cerebral oxygenation measurement in neonates and infants in the clinical setting using the NIRO 300 oximeter," Pediatr. Crit. Care Med. 6, 344-347 (2005).

10. S. Hyttel-Sørensen et al., "Tissue oximetry: a comparison of mean values of regional tissue saturation, reproducibility and dynamic range of four NIRS-instruments on the human forearm," Biomed. Opt. Express 2, 3047-3057 (2011).

11. H. M. Watzman et al., "Arterial and venous contributions to nearinfrared cerebral oximetry," Anesthesiology 93, 947-953 (2000).

12. P. B. Benni et al., "Validation of the CAS neonatal NIRS system by monitoring VV-ECMO patients," in Advances in Experimental Medicine and Biology, P. Okunieff, J. Williams, and Y. Chen, Eds., Vol. 566, pp. 195-201, Springer-Verlag, Boston, Massachusetts (2005).

13. G. A. Marimón et al., "Near-infrared spectroscopy cerebral and somatic (renal) oxygen saturation correlation to continuous venous oxygen 
saturation via intravenous oximetry catheter," J. Crit. Care 27, 314.e13314.e18 (2012).

14. M. Ranucci et al., "Near-infrared spectroscopy correlates with continuous superior vena cava oxygen saturation in pediatric cardiac surgery patients," Pediatr. Anesth. 18, 1163-1169 (2008).

15. P. M. Kirshbom et al., "Cerebral near infrared spectroscopy is a reliable marker of systemic perfusion in awake single ventricle children," Pediatr. Cardiol. 28, $42-45$ (2007).

16. W. J. Levy et al., "The calibration and validation of a phase-modulated near-infrared cerebral oximeter," J. Clin. Monit. Comput. 15, 103-108 (1999).

17. A. Moerman et al., "Relation between mixed venous oxygen saturation and cerebral oxygen saturation measured by absolute and relative nearinfrared spectroscopy during off-pump coronary artery bypass grafting," Br. J. Anaesth. 110, 258-265 (2013).

18. Z. Ricci et al., "Cerebral NIRS as a marker of superior vena cava oxygen saturation in neonates with congenital heart disease," Pediatr. Anesth. 20, 1040-1045 (2010).

19. P. S. McQuillen et al., "Regional and central venous oxygen saturation monitoring following pediatric cardiac surgery: concordance and association with clinical variables," Pediatr. Crit. Care Med. 8, 154-160 (2007).

20. N. Nagdyman et al., "Comparison of different near-infrared spectroscopic cerebral oxygenation indices with central venous and jugular venous oxygenation saturation in children," Pediatr. Anesth. 18, 160-166 (2008)

21. T. A. Tortoriello et al., "A noninvasive estimation of mixed venous oxygen saturation using near-infrared spectroscopy by cerebral oximetry in pediatric cardiac surgery patients," Pediatr. Anesth. 15, 495-503 (2005).

22. W. Knirsch et al., "Regional cerebral oxygenation by NIRS does not correlate with central or jugular venous oxygen saturation during interventional catheterisation in children," Acta Anaesthesiol. Scand. 52, 1370-1374 (2008).

23. J. H. Hansen et al., "Monitoring of regional tissue oxygenation with near-infrared spectroscopy during the early postoperative course after superior cavopulmonary anastomosis," Eur. J. Cardiothorac. Surg. 43, e37-e43 (2013).

24. A. T. Bhutta et al., "Noninvasive cerebral oximeter as a surrogate for mixed venous saturation in children," Pediatr. Cardiol. 28, 34-41 (2007).

25. G. E. Moreno et al., "Regional venous oxygen saturation versus mixed venous saturation after paediatric cardiac surgery," Acta Anaesthesiol. Scand. 57, 373-379 (2013).

26. C. L. Cua et al., "Cerebral saturations trend with mixed venous saturations in patients undergoing extracorporeal life support," Perfusion 19, 171-176 (2004).

27. R. Ginther et al., "Cerebral near-infrared spectroscopy during cardiopulmonary bypass predicts superior vena cava oxygen saturation," J. Thorac. Cardiovasc. Surg. 142, 359-365 (2011).

28. P. E. Daubeney et al., "Cerebral oxygenation measured by near-infrared spectroscopy: comparison with jugular bulb oximetry," Ann. Thorac. Surg. 61, 930-934 (1996).

29. H. Abdul-Khaliq et al., "[Regional transcranial oximetry with near infrared spectroscopy (NIRS) in comparison with measuring oxygen saturation in the jugular bulb in infants and children for monitoring cerebral oxygenation]," Biomed. Tech. 45, 328-332 (2000).

30. M. Redlin et al., "Regional differences in tissue oxygenation during cardiopulmonary bypass for correction of congenital heart disease in neonates and small infants: relevance of near-infrared spectroscopy," J. Thorac. Cardiovasc. Surg. 136, 962-967 (2008).

31. M. Weiss et al., "Near-infrared spectroscopic cerebral oxygenation reading in neonates and infants is associated with central venous oxygen saturation," Pediatr. Anesth. 15, 102-109 (2005).

32. N. Nagdyman et al., "Relation of cerebral tissue oxygenation index to central venous oxygen saturation in children," Intensive Care Med. 30, 468-471 (2004).

33. N. Nagdyman et al., "Comparison between cerebral tissue oxygenation index measured by near-infrared spectroscopy and venous jugular bulb saturation in children," Intensive Care Med. 31, 846-850 (2005).

34. N. Shimizu et al., "Brain tissue oxygenation index measured by near infrared spatially resolved spectroscopy agreed with jugular bulb oxygen saturation in normal pediatric brain: a pilot study," Childs Nerv. Syst. 21, 181-184 (2005).

35. R. N. Kreeger et al., "Evaluation of pediatric near-infrared cerebral oximeter for cardiac disease," Ann. Thorac. Surg. 94, 1527-1533 (2012).

36. B. D. Kussman et al., "Validation of the FORE-SIGHT ${ }^{\circledR}$ pediatric NIRS cerebral oximeter," in (2009).

37. K. Rais-Bahrami, O. Rivera, and B. L. Short, "Validation of a noninvasive neonatal optical cerebral oximeter in veno-venous ECMO patients with a cephalad catheter," J. Perinatol. 26, 628-635 (2006).

38. H. Jeong et al., "Cerebral oxygen saturation measured by near-infrared spectroscopy and jugular venous bulb oxygen saturation during arthroscopic shoulder surgery in beach chair position under sevofluranenitrous oxide or propofol-remifentanil anesthesia," Anesthesiology 116, 1047-1056 (2012).

39. S. H. Choi et al., "Cerebral oxygenation during laparoscopic surgery: jugular bulb versus regional cerebral oxygen saturation," Yonsei Med. J. 54, 225 (2013).

40. D. A. Colquhoun et al., "Non-invasive estimation of jugular venous oxygen saturation: a comparison between near infrared spectroscopy and transcutaneous venous oximetry," J. Clin. Monit. Comput. 26, 91-98 (2012).

41. M. B. Kim et al., "Estimation of jugular venous $\mathrm{O}_{2}$ saturation from cerebral oximetry or arterial $\mathrm{O}_{2}$ saturation during isocapnic hypoxia," J. Clin. Monit. Comput. 16, 191-199 (2000).

42. G. Leyvi et al., "Assessment of cerebral oxygen balance during deep hypothermic circulatory arrest by continuous jugular bulb venous saturation and near-infrared spectroscopy," J. Cardiothorac. Vasc. Anesth. 20, 826-833 (2006).

43. L. C. Henson et al., "Accuracy of a cerebral oximeter in healthy volunteers under conditions of isocapnic hypoxia," Anesthesiology 88, 58-65 (1998).

44. G. Buunk, J. G. van der Hoeven, and A. E. Meinders, "A comparison of near-infrared spectroscopy and jugular bulb oximetry in comatose patients resuscitated from a cardiac arrest," Anaesthesia 53, 13-19 (1998).

45. S. B. Lewis et al., "Cerebral oxygenation monitoring by near-infrared spectroscopy is not clinically useful in patients with severe closed-head injury: a comparison with jugular venous bulb oximetry," Crit. Care Med. 24, 1334-1338 (1996).

46. G. Grubhofer et al., "The contribution of extracranial blood oxygenation on near-infrared spectroscopy during carotid thrombendarterectomy," Anaesthesia 52, 116-120 (1997).

47. A. Ter Minassian et al., "Correlation between cerebral oxygen saturation measured by near-infrared spectroscopy and jugular oxygen saturation in patients with severe closed head injury," Anesthesiology 91, 985-990 (1999).

48. P. Rasmussen et al., "Capillary-oxygenation-level-dependent nearinfrared spectrometry in frontal lobe of humans," J. Cereb. Blood Flow Metab. 27, 1082-1093 (2007).

49. V. Pollard et al., "Validation in volunteers of a near-infrared spectroscope for monitoring brain oxygenation in vivo," Anesth. Analg. 82, 269-277 (1996).

50. V. Pollard et al., "The influence of carbon dioxide and body position on near-infrared spectroscopic assessment of cerebral hemoglobin oxygen saturation," Anesth. Analg. 82, 278-287 (1996).

51. A. Dullenkopf et al., "Cerebral near-infrared spectroscopy in adult patients after cardiac surgery is not useful for monitoring absolute values but may reflect trends in venous oxygenation under clinical conditions," J. Cardiothorac. Vasc. Anesth. 21, 535-539 (2007).

52. J. Schön et al., "Relationship between mixed venous oxygen saturation and regional cerebral oxygenation in awake, spontaneously breathing cardiac surgery patients," Minerva Anestesiol. 77, 952-958 (2011).

53. Y. Harilall et al., "Correlation between cerebral tissue and central venous oxygen saturation during off-pump coronary bypass graft surgery," Perfusion 26, 83-90 (2011).

54. H. Paarmann et al., "Non-invasive cerebral oxygenation reflects mixed venous oxygen saturation during the varying haemodynamic conditions in patients undergoing transapical transcatheter aortic valve implantation," Interact. Cardiovasc. Thorac. Surg. 14, 268-272 (2012).

55. D. C. Lichtenstern et al., "Nahinfrarotspektroskopie in der Sepsistherapie," Anaesthesist 61, 883-891 (2012). 
56. A. Baraka, M. Naufal, and M. El-Khatib, "Correlation between cerebral and mixed venous oxygen saturation during moderate versus tepid hypothermic hemodiluted cardiopulmonary bypass," J. Cardiothorac. Vasc. Anesth. 20, 819-825 (2006).

57. H. Paarmann et al., "Agreement of noninvasive cerebral oxygenation with mixed venous oxygen saturation in patients undergoing ECMOtherapy," ACP 15, 55-61 (2011).

58. C. Koch et al., "Prospective evaluation of regional oxygen saturation to estimate central venous saturation in sepsis," J. Clin. Monit. Comput. 29, 443-453 (2015).

59. M. S. Ali et al., "Spatially resolved spectroscopy (NIRO-300) does not agree with jugular bulb oxygen saturation in patients undergoing warm bypass surgery," Can. J. Anaesth. 48, 497-501 (2001).

60. K. Yamashita et al., "Cerebral oxygenation monitoring for total arch replacement using selective cerebral perfusion," Ann. Thorac. Surg. 72, 503-508 (2001).

61. K. Yoshitani et al., "Clinical validity of cerebral oxygen saturation measured by time-resolved spectroscopy during carotid endarterectomy," J. Neurosurg. Anesthesiol. 25, 248-253 (2013).

62. J.-L. Fellahi et al., "Cerebral and somatic near-infrared spectroscopy measurements during fluid challenge in cardiac surgery patients: a descriptive pilot study," J. Cardiothorac. Vasc. Anesth. 27, 266-272 (2013).

63. D. B. MacLeod et al., "Development and validation of a cerebral oximeter capable of absolute accuracy," J. Cardiothorac. Vasc. Anesth. 26, 1007-1014 (2012).

64. K. Ikeda et al., "The accuracy of a near-infrared spectroscopy cerebral oximetry device and its potential value for estimating jugular venous oxygen saturation," Anesth. Analg. 119, 1381-1392 (2014).

65. J. M. Bland and D. G. Altman, "Measuring agreement in method comparison studies," Stat. Methods Med. Res. 8, 135-160 (1999).

66. R. M. Schell and D. J. Cole, "Cerebral monitoring: jugular venous oximetry," Anesth. Analg. 90, 559-566 (2000).

67. R. G. Wijbenga, P. M. A. Lemmers, and F. van Bel, "Cerebral oxygenation during the first days of life in preterm and term neonates: differences between different brain regions," Pediatr. Res. 70, 389-394 (2011).
68. P. M. A. Lemmers and F. van Bel, "Left-to-right differences of regional cerebral oxygen saturation and oxygen extraction in preterm infants during the first days of life," Pediatr. Res. 65, 226-230 (2009).

69. H. Sørensen et al., "Cutaneous vasoconstriction affects near-infrared spectroscopy determined cerebral oxygen saturation during administration of norepinephrine," Anesthesiology 117, 263-270 (2012).

70. J. R. Feiner, J. W. Severinghaus, and P. E. Bickler, "Dark skin decreases the accuracy of pulse oximeters at low oxygen saturation: the effects of oximeter probe type and gender," Anesth. Analg. 105, S18-S23 (2007).

71. P. E. Bickler, J. R. Feiner, and J. W. Severinghaus, "Effects of skin pigmentation on pulse oximeter accuracy at low saturation," Anesthesiology 102, 715-719 (2005).

72. T. J. Germon et al., "Cerebral near infrared spectroscopy: emitter-detector separation must be increased," Br. J. Anaesth. 82, 831-837 (1999).

73. T. W. Hessel, S. Hyttel-Sørensen, and G. Greisen, "Cerebral oxygenation after birth-a comparison of INVOS ${ }^{\circledR}$ and FORE-SIGHT ${ }^{\mathrm{TM}}$ nearinfrared spectroscopy oximeters," Acta Paediatr. 103, 488-493 (2014).

74. B. F. Matta and A. M. Lam, "The rate of blood withdrawal affects the accuracy of jugular venous bulb. Oxygen saturation measurements," Anesthesiology 86, 806-808 (1997).

75. S. Hyttel-Sørensen et al., "Calibration of a prototype NIRS oximeter against two commercial devices on a blood-lipid phantom," Biomed. Opt. Express 4, 1662 (2013).

76. S. Kleiser et al., "Comparison of near-infrared oximeters in a liquid optical phantom with varying Intralipid and blood content," Adv. Exp. Med. Biol. 876, 413-418 (2016).

77. S. Kleiser et al., "Comparison of tissue oximeters on a liquid phantom with adjustable optical properties: an extension," Biomed. Opt. Express 9, 86-101 (2018).

78. S. Suzuki et al., "A tissue oxygenation monitor using NIR spatially resolved spectroscopy," Proc. SPIE 3597, 582-592 (1999).

79. M. L. G. Mikkelsen et al., "The influence of norepinephrine and phenylephrine on cerebral perfusion and oxygenation during propofolremifentanil and propofol-remifentanil-dexmedetomidine anaesthesia in piglets," Acta Vet. Scand. 60, 8 (2018).

Biographies of the authors are not available. 